\title{
Kaljutaieste otsinguil Eestis ja Karjalas
}

Tiiu Ernits ja Enn Ernits

\section{Eestis}

\section{Esmateadet kontrollimas}

Eestist pole seni muistseid kaljuraiendeid leitud, kuigi nende avastamine rändrahnudelt pole sugugi võimatu. 150 aasta eest pidas Johann Samuel Boubrig (1788-1852) Õpetatud Eesti Seltsi koosolekul ettekande eestlaste muistsest usundist Otepää kihelkonnas. Muu hulgas mainis kõneleja, et mõne versta kaugusel Palupera mõisast kasvanud okaspuuhiis, kus muiste ohverdatud Toorile või Torole. Hiie lähedal leidunud neljakandiline tahutud kivi, alt laiem kui pealt. Sellel olnud näha igasuguseid, tõenäoliselt sisseraiutud kujutisi (allerlei wahrscheinlich eingehauene Figuren). Kahjuks polnud asjatundjad kivi näinud, sest mõni aasta enne mainitud ettekande pidamist olevat see müüritud mingi ehitise sisse (Boubrig 1843: 92-93; Krohn 1894: 29).

Küsitlesime 1988. aasta juunis Paluperas ekspeditsioonil viibides kohalikke elanikke. Paraku ei õnnestunud saada mingeid andmeid nimetatud kivi kohta. Autoreile teatati vaid ühest nn jäljekivist Adra külas. Kohapeal osutusid selle ebakorrapärased süvendid looduslikeks. Pärimusi kiviga seoses enam ei teatud. Hiie asukohta aitaksid ehk täpsustada vanad mõisakaardid.

\section{Jaan Jungi jälgedes}

Esimene eesti asjaarmastaja-arheoloog Jaan Jung (1898: 7, 40; 1910: 32; Tomson 1910) on kirjeldanud paari raienditega kivi (joonis 1-2).

Pärnu maakonnas Halliste kihelkonnas Abja-Mulgi talu lähedal olevat leidunud võib-olla kivikalmest pärit kaks mitmepuudast märkidega rahnu. Üks neist olevat linaleotamisel (Halliste?) jõkke vajunud, teine aga saanud J. Jungi valdusse, kes tegi märkidest 


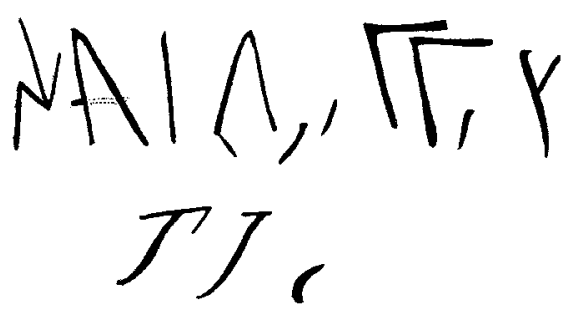

Joonis 1. Kujutised Halliste kivil (Tomson 1910).

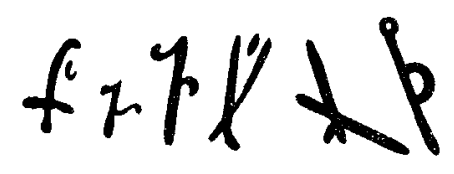

Joonis 2. Kujutised Nuia kivil (Tomson 1910).

koopia ja läkitas selle ruunispetsialistile professor Sophus Buggele Norrasse Christianiasse. Viimane vastanud, et tegu pole muinasskandinaavia ega üldsegi Euroopa kirjatähtedega. Kivil asetsevad märgid olevat tema arvates üsna sarnased Siberist avastatud turgi ruunikirjaga. Asjaomased märgid meenutavad siiski (vähemalt osaliselt) normaalseid või ümberpööratud ladina tähti, mis ei tohiks vähendada teadlaste huvi nende vastu.

J. Jung on käsitlenud veel Nuia alevis ühe maja seina sisse müüritud kivi, millele olevat olnud raiutud omapärased sümbolid (mõõgakujuline jm). Veel mainis ta, et Järvamaalt Sargvere mõisa põllult olevat leitud iseäralike figuuridega kivi, mis maamõõtja oletusel kujutavat vanaaegset kaarti(!).

1988. aasta augustis otsisime J. Jungi elupaigas, endise Kaidi vallakooli ümbruses asjaomast kivi, kahjuks tulemusteta. See viitab ennekõike sellele, et oleks vaja tutvuda arhiividesse ja muuseumidesse seni kogutud materjaliga kivikujutiste kohta ning objektid kohapeal üle vaadata. Enne Esimest maailmasõda avaldatud üleskutses märgiti, et tuleb koguda andmeid igasuguste kirjadega või kirjadeta mälestus- või hauakivide kohta, kusjuures kirjad ja märgid tuleksid võimalikult truult ära joonistada, niisama ka kivi või risti oma kuju (Reimann \& Thomson 1911: 129-130). Kõik rahvasuus väidetu pole teatavasti täpne. Näiteks teatati, et Paistu kihelkonnas Heimtali vallas Torimu talu karjamaal leidunud kivil olevat võõraste tähtedega kiri, mille kohta nentis J. P. Sõggel kohapeal, et see on siiski looduse kätetöö (Sõggel 1910: 114). 


\section{Väikeselohulisi kultuskive avastamas}

Eestis on seni avastatud ligikaudu 1750 väikeselohulist kultuskivi ehk lohukivi. Lõuna-Eestist on neid leitud aga kõigest 54 (Tvauri 1999: 115-119). Teadaolevalt on Kambja kant Tartumaal asustatud hiljemalt varajasel rauaajal. Kaua aega oli sealt teada vaid üks lohukivi Kullaga külas.

Suur-Kambja küla Lehola talu hoonetest umbes 50 meetri kaugusel loode suunas asetseb põllul suur rändrahn (joonis 3). 1988. aasta mais leidis Tiiu Ernits sellelt kaks kõrvuti paiknevat ligikaudu poole sentimeetri sügavust ja 5 sentimeetrise läbimõõduga ühtlaselt ümarat nagu kulbipõhjaga vajutatud lohku. Rahn jääb Kullaga lohukivist ligikaudu 5 kilomeetri kaugusele.

Lehola rändrahnu juures turgatas metsatehnik Mart Eensalu pähe sealt umbes poole kilomeetrit edela poole Peeda oja käärus asuv suur kivirahn (joonis 4). Looklev oja lõikab Tartu-Võru maan-

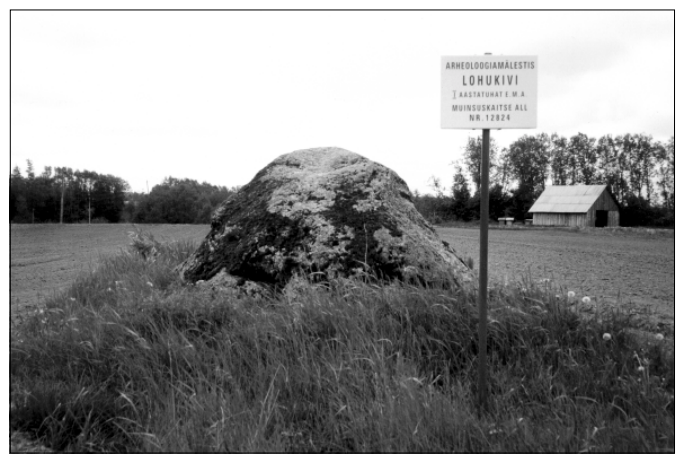

Joonis 3. Lohukivi Suur-Kambja põllul. Foto: E. Ernits 2000.

Joonis 4. Lohukivi Suur-Kambjas Peeda ääres. Foto: E. Ernits 1988.

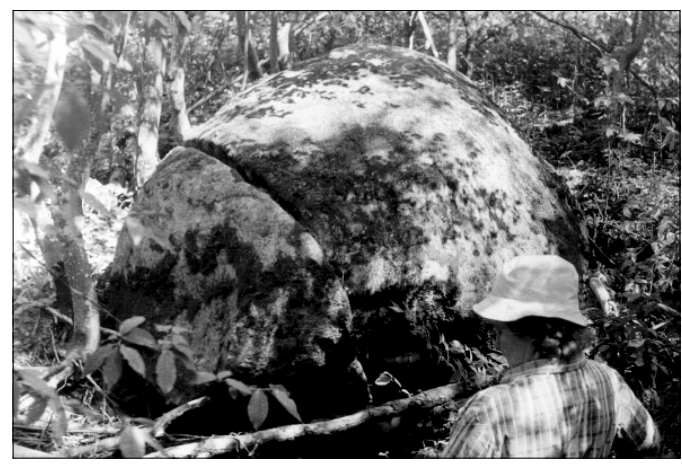


Joonis 5. Lohud Peeda (Suur-Kambja) kultuskivil. Visand: T. Ernits ja H. Kurss 1988, 1991.

teed umbes 1,5 kilomeetril VäikeKambjast Võru pool. Oja voolab sügavas orus, mille pervedel kasvavad

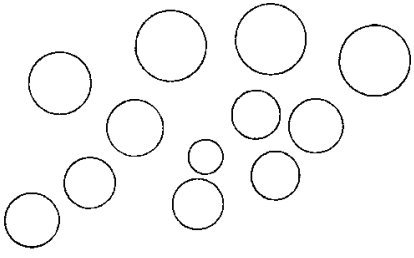
tihedalt lehtpuud. Rändrahn paikneb kahest ojaharust piiratud saarekesel (ca $50 \times 30$ $\mathrm{m})$ ligikaudu 10 meetrit allavoolu oja hargnemise kohast, ulatudes ühe küljega vette.

Kivi suurim pikkus idast läände on $3,3 \mathrm{~m}$, laius 2,9 m ning kõrgus mullapinnast 1,3
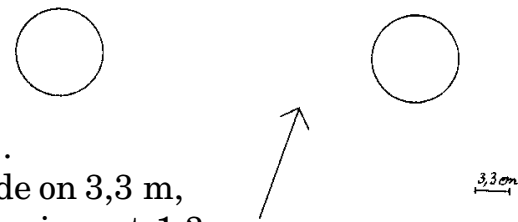
ja ojapõhjast 2,3 meetrit. Rahnu ojapoolses osas äratab tähelepanu sügav põhja-lõunasuunaline lõhe. Näidatud kivi on üldiselt sammaldunud, kuid selle kõrgeimas osas leiti viis suuremat (läbimõõduga 6-7 cm) ja kaheksa väiksemat reljeefset siledapõhjalist ning paar ebaselget kareda pinnaga lohku (joonis 5). Praegu on mõlemad kirjeldatud kivid muinsuskaitse all.

\section{Kuradikivi Antsla lähedal}

Pärast Enn Ernitsa ettekande "Karjala petroglüüfiq: miiq esiissi usk om kivvi raot" kuulamist Kaika suveülikoolis Loosis 1990. aasta suvel jutustas võru keele ja kultuuri arendaja Jaan Pulk, et Antsla lähedal Oe külas on huvipakkuv kivi, millesse võib olla raiutud selline luigekujutis, nagu neid on tehtud Karjalas.

Alles 1991. aasta 12. augustil onnnestus meil nimetatud kivi vaatama minna. Rahnu olevat kutsutud vist Kuradikiviks, mainis meid lahkelt metsa serva toonud J. Pulk ja lisas, et väidetavasti oli kivi seotud nõidumisega.

Väliselt meenutab Oe kivi paati. Sellise kujuga rändrahne kutsutakse Lõuna-Eestis Vanapagana lootsikuiks. Rahnul on pikkust veidi üle kolme ja laiust üle kahe meetri; selle kõrgus maapinnast on ligi poolteist meetrit. Kivi pealispinnal hakkavad silma raiutud kujutised (joonised 6-7).

Lähemal uurimisel meil luigekujutist leida ei õnnestunud: keret meenutav ovaal osutus looduslikuks murendiks. Kindlasti kuulu- 


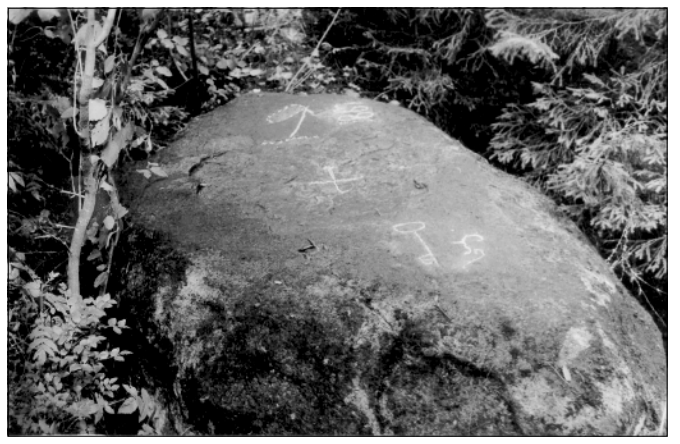

Joonis 6. Oe Kuradikivi üldvaade. Foto: E. Ernits 1991.

Joonis 7. Kirjatähe ja võtme kujutis Oe Kuradikivil. Foto: E. Ernits 1991.

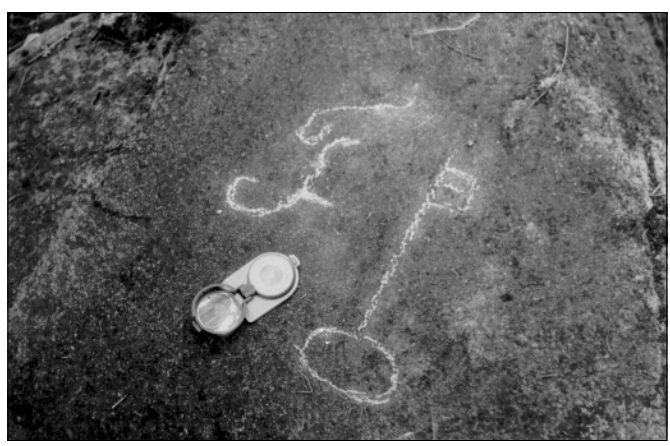

vad raiendite hulka kaks teineteisega teravnurga all ühendatud joont, mille tähendus pole kahjuks mõistetav, sest ilmselt on tuletegemise ja risti sisseraiumisega kujutis suurel määral hävinud. Üle 10 sentimeetri pikkuste harudega rist võib olla raiutud samal ajal aastaarvuga 1867. Rahnul kujutise kirdesuunalises vastasotsas leidub $33 \mathrm{~cm}$ pikkune võtmekujutis ja sellest mõnevõrra väiksem kirjatäht T või (vähem tõenäoliselt) F. Need näivad ristist ja aastaarvust ajaliselt vanemad olevat; viimased on poole sügavamalt raiutud (4-6 $\mathrm{mm})$.

Allpool esitatud muistendist ilmneb, et kohalikule rahvale meenutas see triikrauda. Kivirahnu kohta on avaldatud kaks muistendit (Laugaste \& Liiv 1970: 227, 244-245). Esimese neist on üleskirjutaja V. Nummertile 1956. aastal jutustanud Oe küla elanik Ida Tamm (snd 1889):

[---] Kivi peal on jälg, mis sarnaneb inimese jäljele, ja see olevat Kuradi jälg [---] Kivi all pidi olema raha-või kullakast ja oli sinna 
pantud kellegi rikka mõisniku poolt. Mõisnik pani selle kulla või raha sellepärast metsa, et keegi kätte ei saaks. Mõisnik olevat mü̈̈nud selle kulla Kuradile. Kätte saavat see, kes annab ära kellegi hinge. Keegi julge mees tahtnud seda kulda omale ja lubanud oma naise hinge Kuradile. Läinud mees öösel kell 12 kivi kaevama, sel ajal naine kodus näinud, kuidas õue sõidab keegi nelja musta hobusega; naine hakanud kartma ja jooksnud naabermajja. Tõld keeranud ümber ja läinud ära. Mehel olevat juba kasti äär käes olnud, aga et kuradid naist kätte ei saanud, langenud kast kolinaga tagasi. Mees jäänudki kullast ilma. See mees olevat tõesti elanud endises Oe külas [---]

Ilmselt sama kivi kohta on teise muistendi 1958. aastal paberile pannud Antsla keskkooli viienda klassi õpilased:

Õru metsas on suur kivi, mille all olevat Vanapagan suure rahapajaga. Ta istub kivi all ja segab käpaga raha. Mõnigi olevat jaanipäeva öösel seda kõlinat kuulnud. Enne kivi alla minekut maalinud ta kivile oma jälje, võtme ja triikraua. Ta teinud seda selleks, et keegi tema rahalugemist ei kuuleks ega segaks. Keegi ei saavat kivi üles kangutada.

Oe kivi on Aime Maripuu vahendusel jõudnud ka ilukirjandusse ja selle on folklorist Marju Kõivupuu tõlkinud peakirja all "Oe külä naasõ heng” võrukeelsele lugemikule (Võrokõstõ, 1993: 207-209; Võrokiilne, 1995: 291-293).

Edaspidist selgitamist ootavad Oe kiviga seonduvad küsimused: Kas see on olnud ka piirikivi või raiuti rist kivvi kurivaimu peletamiseks? Mida tähendavad võti ja T-täht? Kas seda kasutati kultuskivina?

\section{Karjalas}

\section{Lohukivi Karjalas}

12. augustil 1985 leidsime Äänisjärve läänerannikul sajakonna kilomeetri kaugusel Petroskoist lõuna pool asetseva vepsa küla Kaskeza lounaotsa (vepsa 'Suvagd') juurest veepiirilt kandilise tehislohkudega kivi (joonis 8). Nende paigutuses on tuntavaid ühisjooni Äänisjärve idakaldal Peri VI neemikule tehtud selenomorfide ehk kuutaoliste raienditega ning ühe Skandinaavia hauakivi süven- 


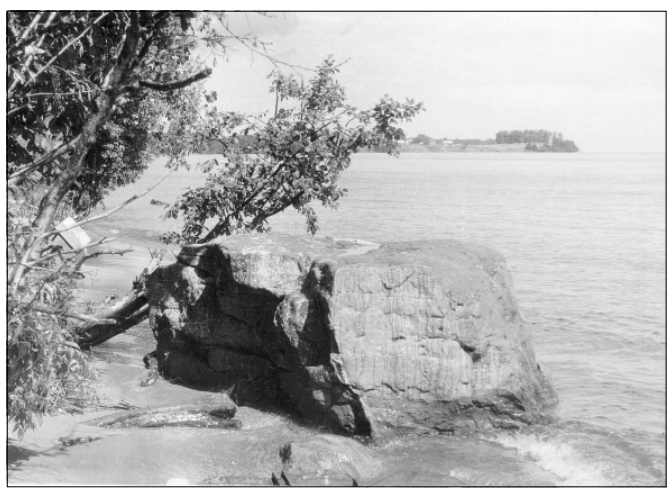

Joonis 8. Lohukivi Kaskezas Ä̈̈nisjärve läänekaldal. Foto: E. Ernits 1988.

Joonis 9. Lohud Kaskeza kultuskivil. Foto: $E$. Ernits 1988.

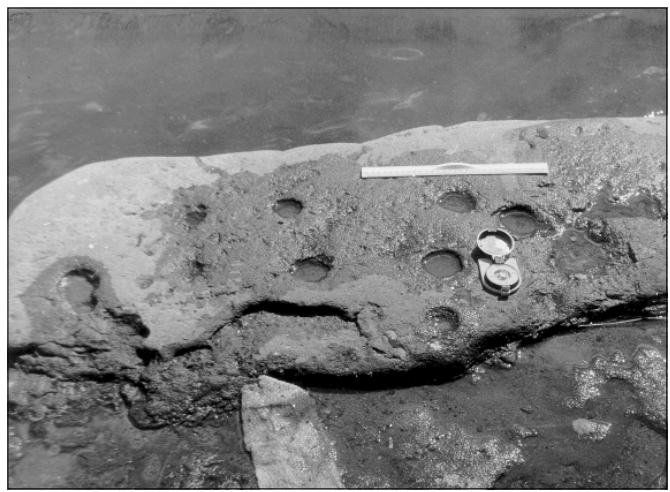

dite asenditega (vt Ernits 1987: 87; Äyräpää 1942: 185, 188). Kaskeza kivi on praegu teadaolevaist lohukividest Põhja-Euroopas kõige idapoolsem. Eestist ida pool oli neid 1990ndate aastate alguseni arheoloog Vello Lõugase suulistel andmetel leitud Karjala kannasel ja Ilmeni järve ääres Novgorodi kandis; praeguseks on Karjalast avastatud teisigi.

22. juulil 1988 uurisime Kaskeza kivi detailsemalt (joonis 9). See paikneb peaaegu paralleelselt tublisti üle 5 meetri kõrguse vertikaalse liivakivist kaldaga, jäädes sellest kolme ja enama meetri kaugusele. Kivi pikkuseks saime 2,6 ja laiuseks 2 meetrit. Rahn on lääneotsast ligikaudu $75 \mathrm{~cm}$, keskelt aga järvepoolses osas veepinnast 1,3 meetri kõrgune, kalda poolt paari-kolmekümne sentimeetri võrra madalam. Hallikaspruuni kivi idapoolses osas leidub ligi kolmesentimeetrine kõrgendik, mille serv ristub kivi pikiteljega otsast umbes 50-60 sentimeetri kaugusel. 
Põhjapoolseim lohk, mis tundub looduslikuna, on kingakujuline, meenutades Äänisjärve petroglüüfide piirkonna selenomorfe. Ülejäänud lohud on enam-vähem ümarad 4,0-6,7 sentimeetrise läbimõõduga ja 0,6-2,1 cm sügavused. Teistest väiksemad $(4,0-4,7 \mathrm{~cm})$ ja madalamad $(0,6 \mathrm{~cm})$ on nelinurkse asendiga lohkudest kaks järvepoolset.

\section{Jumala Jalake}

Saime 15. juulil 1987 Šalas endise Bessov Nossi küla elanikult Maria Filippovalt (snd 1925) teada, et küla ja Äänisjärve vahel asetseb inimese jalajälge meenutava süvendiga kivi, mida kutsutud vene keeles Bogovaja Nožka'ks 'jumala jalake”. Praegu Pudožis elav Jefim Titkov (snd 1908) mäletas, et Bessov Nossist Modoža poole viiva teeäärsel štšelja'l (kohalikus murdes 'kalju') leiduva jalajäljega mõõtnud lapsed oma jalapikkust ( $v$ detstsve vse pomerjali nožku svoju). See võib näidata, et kiviga seotud uskumused, kui need varem ka eksisteerisid, olid hääbunud juba enne Esimest maailmasõda.

21. juulil 1987 leidsime Bogovaja Nožka üles. See paikneb endisest Bessov Nossi külast põhja poole Modoža randa viiva tee servast paremal umbes ühe meetri kaugusel, külast ligikaudu poole kilomeetri ja metsaservast 200 meetri kaugusel. Kivi on 93 sentimeetri pikkune, laiemast kohast $50 \mathrm{~cm}$, kitsamast $31 \mathrm{~cm}$ lai ning maapinnast umbes $35 \mathrm{~cm}$ kõrgune (joonis 10). Kivi läheduses kasvavad suhteliselt hõredalt poole meetri jämedused männid. Umbes kolme meetri kaugusel rahnust leidub umbekasvav allikas, mida olid

Joonis 10. Jumala Jalake endises Bessov Nossi külas Ä̈̈nisjärve idakaldal. Visand: E. Ernits 1987.

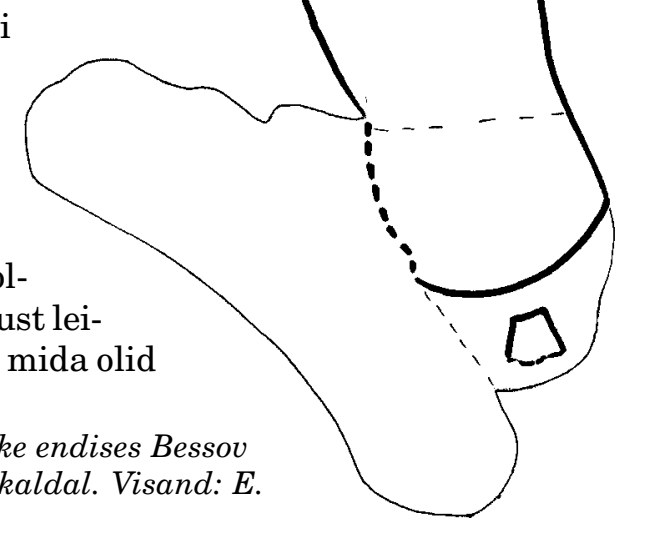


maininud ka informandid. Jalajälje kujutis on looduslik. Selle kogupikkus on 18, laius kannast 5 ja jalalabast 9 sentimeetrit. Jälg paikneb tee suhtes risti, varbaid meenutav osa lääne poole. Nagu osutab kivi nimetus, on seda "jälge" peetud Jumala jalajäljeks nagu mujalgi Põhja-Venemaal.

\section{Teated Põdrakivist}

18. juulil 1988 teatasid Vodla keskjooksul paiknevas Kubovos elavad Maria Fepjonova (snd 1910) ja Nikolai Fepjonov (snd 1948), et asulast 3-4 kilomeetrit ülesvoolu leiduvat jões päris kalda lähedal vähemalt 4 meetri pikkune Los Kamen (Põdrakivi). Kohanime osiste nominatiivne liitumine osutab algselt läänemeresoome päritoluga toponüümile. Taisja Krõssanova (snd 1913) ema näinud varahommikul alasti naist (näkineidu) end lamedal kivil pesemas. Teda silmates hüpanud naine vette. T. Krõssanova isa maininud, et rahnule, mida nimetatud Losja Ludaks, olevat raiutud mingid tähed (võbitõ bukvõ). 50-55 aasta vanune Aleksandr Šikov, kes käis seal igal aastal heina tegemas, pole kivil raiendeid märganud. Tema teada paikneb see umbes 6 meetri pikkune kivi 6 kilomeetri kaugusel Kubovost. 1988. aastal, mil veetase oli kõrge, katnud kivi ligi $30 \mathrm{~cm}$ paksune veekiht. Mainitud informandi teatel ei meenutavat Los kamen üldsegi põtra. Pigem olevat ta oma nime saanud läheduses, kaldast paarisaja meetri kaugusel metsas asetseva lõhega kivi järgi, mis meenutavat põdrapead.

Kubovo kandis tasuks otsinguid jätkata. J. Ch. Stuckenberg (1844: 571) mainis Vodlas metsaga kaetud saart Laplandska, mis võib seonduda muistsete saamidega. Tänapäeval kannab see kärestikuga sama nimetust Voibutš, mille tähendus on veel selgitamata.

\section{XX sajandi raiendid}

Huvi pakuvad ka suhteliselt hilised raiendid. Siinkohal olgu esitatud mõned näited koos seletustega, mida nende kohta oskasid anda kohalikud elanikud. 17. augustil 1986 näitas Kaskezas vepslanna Anna Kabakova palvel ta lapselaps meile Äänisjärve kaldalähedases vees tumedat kivirahnu, mille ühele vertikaalküljele oli raiutud profiilne mehepea kujutis, kusjuures selle kael ulatub vette. 


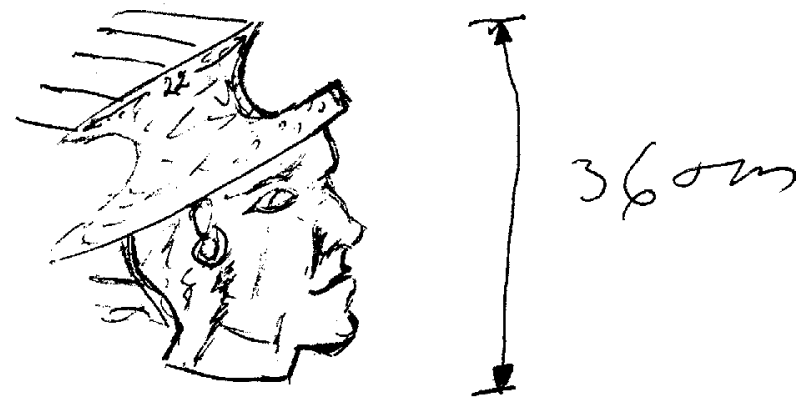

Joonis 11. Kivi ees- ja tagakülje

kujutised Kaskezas Ä̈̈nisjärve lä̈̈-

nekaldal. Visandid: T. ja E. Ernits 1986.

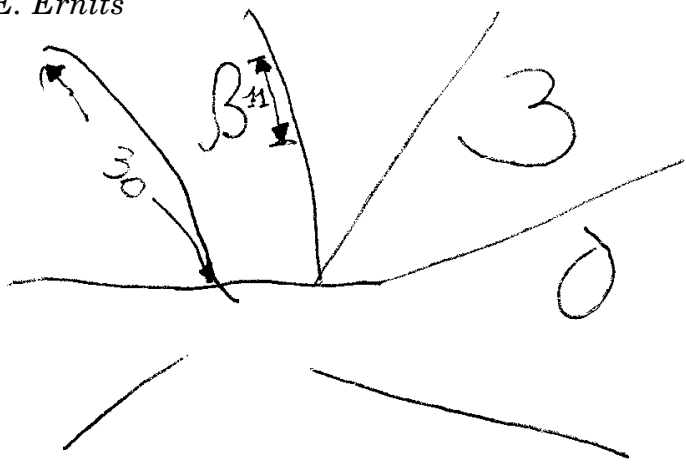

Kujutise kõrgus oli 36 sentimeetrit veepinnast. Peas oli tal omapärane alasikujuline müts. Selle 22 sentimeetri pikkusest alaosast suundusid tahapoole 5 paralleeljoont. Kivi vastasküljelt leidsime omapärase joonestiku ning kirillitsa B, 3 ja O-d meenutavaid kujutisi (joonis 11). Need võisid olla kellegi initsiaalid. Hämaruse ja välklambi puudumise tõttu ei õnnestunud kivi pildistada.

1988. aasta suvel otsisime sama kivi edutult. Jäi teadmata, kas see jäi leidmata kõrgema veeseisu või jäätriivi tõttu. Avastasime järves lebavailt kividelt vaid poole sajandi vanuseid raiendeid, mille kohta küsisime teavet kohalike vepslaste käest.

Üks otsvaates kolmnurkne initsiaalidega kivi paikneb Äänisjärve ääres kaldaliival veepiiri lähedal ja selle ühele kaldpinnale on raiutud vene tähed FTZ I STZ (joonis 12). Kohaliku vepslase Nikolai Antsiferovi teatel tähistanud need naabritalu vepsa poisse Fjodor ja Stepan Trofimovitš Zahharinit. 


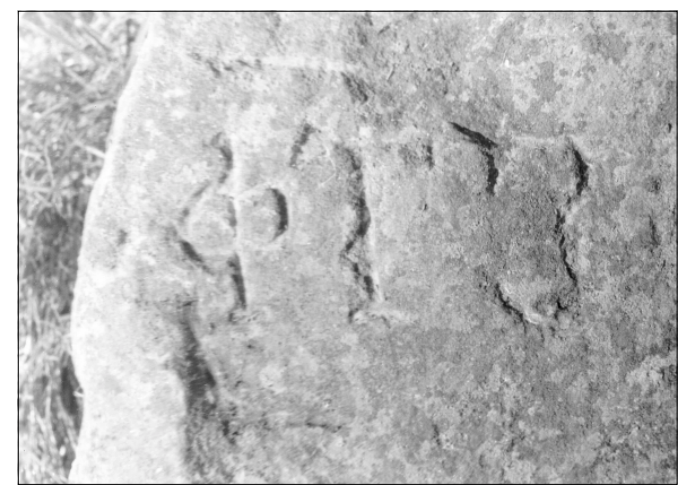

Joonis 12. Venekeelsed nimetähed FTZ Kaskeza kivirahnul. Foto: E. Ernits 1988.

Kaldalähedasest veest leidsime tunduvalt suuremate mõõtmetega lameda pealispinnaga kivi. Sellele oli raiutud järgmine tekst: 1928 g, Pamjati VG, Na pamjat G. A., St. Zah. Seega on selle teksti kivvi raiunud eespool mainitud S. T. Zahharin. Pamjati VG, Na pamjat tähendab vene keeles 'mälestuseks'. G. A. tähendab N. Antsiferovi arvates kas Andrei Gašinit või Grigori Antsiferovit (tõenäolisemalt viimast), V. G. aga Vassili Gašinit. Initsiaalid olevat kivvi raiutud hukkunud eakaaslaste mälestuseks.

Bessov Nossi lääneneemikule on raiutud kiviaegsete petroglüüfide sekka R. M. P. r. 1937 g., mis M. Filippova teatel tähistab kohaliku elaniku Mihhail Pavlovitš Rjamzini sündi; väike $\mathrm{r}$ on lühend sõnast rodilsja 'sündinud'.

\section{Muud huvitavat}

Ekspeditsioonide käigus õnnestus Karjalas talletada huvitavat teavet ka kohanimede, uskumuste jm kohta. On üldiselt teada, et legende, mis seostuvad petroglüüfidega, on ülimalt vähe. Seda tähtsamad on andmed kohalike elanike arvamustest nende vanuse ja tekke kohta ning suhtumine neisse.

Äänisjärve petroglüüfe on kohalik elanikkond pidanud pühaks. Arvati, et need on jumala tehtud - nagu väitis M. Filippova: Eto vsjo bogovo. Raiendeid varem ei rikutud.

Huvitavat uurimisainet pakuvad ametlike kohanimede rahvapärased paralleelid. Tšornaja Retška (eesti k Mustjõe) suudmes olevat saarekest, kus leidub ka petroglüüfe, kutsutakse mitme infor- 
mandi teatel Korešnitsaks, sest seal püütud tinti. Vene keele kohalikus murdes on see korehha, läänemeresoomlastelt laenatud sõna (karjala kuoreh, vepsa koreh) (Fasmer 1986: 325).

Oktoobris hakati Äänisjärvel lutsu püüdma. See oli talvise toiduna hinnatud kala, mida söödi ka pulmapeol (M. Filippova teade). Mitme informandi väitel kutsuti järveranda Peri neemelt Karitski neemeni Bližnjaja (Lähis-) Modožaks, edasi Šala poole aga Dalnjaja (Kaug-) Modožaks. Praegu kannab kirjanduses Modoži nime üks petroglüüfidega saareke. Kohalik rahvas nimetas seda aga lihtsalt Ostrovokiks ('saareke'). Kirjapandud teave kinnitab oletust, et Modoža nimetus võib olla lähtunud karjala ja vepsa sõnast madeh 'luts' (Ernits 1986: 247).

J. Titkov mainis, et Karitskije Nossõ, kus mitut neemekest eraldavad väikesed lahed ja millel on arvukalt kaljuraiendeid, nimetus tuleneb kohalikust vene sõnast karitsa 'laheke'. Karitsa on deminutiiv põhjavene sõnast kara 'laht', mis lähtub omakorda vepsa sõnast kar 'laht; auk' (Fasmer 1986: 189). Seepärast tuleks senise Karetski Nossi asemel kasutada nimetust Karitski Noss. Peri Nossi tarvitasid kohalikud reaalsusest lähtuvalt ka mitmuses - Peri Nossõ.

Kohalikel petroglüüfidel on sage veelinnu motiiv. Viimase poolteise sajandi üleskirjutused viitavad austavale suhtumisele ja sama peegeldavad ka meie intervjuud. Tatjana Senina (snd 1932, Onežski < Bessov Nossi k) jutustas, et kohalikud venelased - läänemeresoomlased on Äänisjärve idarannikul juba aastasadade eest hääbunud - pidasid hanesid ja luiki pühadeks lindudeks. Veelindudest tapetud vaid parte. Teisalt on teada, et ei sööda just nimelt pardiliha (Brjussov 1940: 118). Informandi isa polevat lubanud isegi kajakamune korjata, lausudes, et patt on linnult mune ära võtta. M. Filippova ei maininud küll midagi kajaka-ja pardimunade korjamise keelust, kuid mäletas uduselt, et hane peetud tsaarilinnuks (naverno, tsarskaja ptitsa). Ivan Krõsanov (snd 1915) nimetas tsaarilinnuks hoopis luike, kes olevat nagu naisterahvas (vt ka Autio 1987: 72). Tema abikaasa Taissa meenutas, et isa lasknud kalapüügil suure havi vette tagasi, sest muidu kaduvat kalad rannavetest. Neis pärimustes kajastub soome-ugri jahimeeste ja kalastajate maailmakäsitluse ülekandumine põhjavenelastele. 


\section{Lõpetuseks}

Elias Lönnroti värsiga "Kalevalast" kirjutti kivehen kirjan 'kirjutas kivvi raamatu' seoses oletas kaljutaideuurija Eero Autio (1981: 152), et sõna kirjutama võis varem tähendada sõnumi kivvi raiumist. Sellele võiks kaudselt viidata ka ajakirjast nopitud karjala vanasõna Lapsennu opastettu on gu kiveh kirjutettu (Karjalaisia 1987: 190).

\section{Kirjandus}

Autio, E. 1981. Karjalan kalliopiirrokset. Helsinki: Otava.

Autio, E. 1987. Joutsen - karjalaisten pyhä lintu Äänisen kalliokuvissa 1 . Karjalan heimo 5/6, lk 70-75.

Boubrig, J. L. 1843. Zur nähern Kenntniss der Volkssagen und des Aberglaubens der Ehsten aus dem Kirchspiele Odenpä. Verhandlungen der Gelehrten Estnischen Gesellschaft 1, 2, lk 79-93.

Brjussov, A. J. 1940. Istorija drevnei Karelii. Trudõ Gosudarstvennogo Istoritšeskogo muzeja 9. Moskva.

Ernits, E. 1986. O proishoždenii nekotorõhh toponimov na poberežje Onežskogo ozera. Sovetskoje finno-ugrovedenije 4, lk 246-248.

Ernits, E. 1987. Maast ja taevakehadest Äänisjärve kaljuraienditel. Tartu Tähetorni kalender 1988. aastaks. Tallinn: Valgus, lk 82-89.

Fasmer, M. 1986. Etimologitšeski slovar russkogo jazõka 2. Moskva.

Jung, J. 1898, 1910. Muinasaja teadus Eestlaste maalt 2, 3. Jurjev.

Karjalaisia sanaanlaskuja 1987. Punalippu 5.

Krohn, J. 1894. Suomen suvun pakanallinen jumalanpalvelus. Helsinki.

Laugaste, E. \& Liiv, E. 1970. Muistendid Vanapaganast. Monumenta Estoniae Antiquae II. Eesti muistendid. Hiiu- ja vägilasmuistendid III. Tallinn.

Reimann, W. \& Thomson, A. 1911. Üleskutse muinasaegiste mälestuste korjamiseks. Eesti Kirjandus 4, lk 129-131.

Stuckenberg, J. Ch. 1844. Hydrographie des Russischen Reiches 1. Sankt-Petersburg.

Sõggel, J. P. 1910. Vanavara J. Jungi Muinasaja teaduse II ande täienduseks. Eesti Kirjandus 3, lk 107-114.

Tomson, A. 1910. Kas Eestlastel on oma kirjamärkisid? Eesti Kirjandus 3, lk 81-91.

Tvauri, A. 1999. Cup-marked Stones in Estonia. Folklore 11, lk 113169.

Võrokiilne lugõmik 1995. Võro.

Võrokõstõ lugõmiseraamat. 1993. Tallinn.

Äyräpää, A. 1942. Uhrikivi - kipujenkivi. Kalevalaseuran vuosikirja 22. Helsinki, lk 179-208. 